lambs. The fourth animal, No, 190/63, shed the organism in the urine for a period of 4 months. It should be mentioned that in two lambs which showed corresponding symptoms in September 1965 no Borrelia-like organisms could be demonstrated.

So far, it is impossible to decide whether there is any connexion between the disease and the presence of these organisms in the urine. Nevertheless, it is remarkable that the organisms were demonstrated in three of the eight diseased animals, and in addition that they were found in four apparently healthy animals, three of which had been in close contact with the individuals attacked. Furthermore, the plant Narthecium ossifragum could not cause photosensitization so late in the summer as September.

Whatever the relation of these organisms to the disease, they are nevertheless of importance, because they resemble leptospirae.

I thank Prof. H. Stormorken for his advice and helpful suggestions in preparing this manuscript.

\section{Arne HJelle}

State Veterinary Research Station for Sheep, Sandnes, Norway.

\section{MICROBIOLOGY}

\section{"Soluble" Antigens from Cells infected with Rabies Virus}

A CLOSE correlation has been found between infectivity and the amount of antigen in the fractions obtained after rate zonal centrifugation of rabies virus partially purified by differential high speed centrifugation ${ }^{1}$; but nevertheless more than 90 per cent of antigen or antigens remain in the virus-free supernatant fluids after high speed centrifugation of crude infectious tissue culture material. As the soluble antigen(s) may play an essential part in immunization against rabies virus, further experiments were undertaken to characterize them.

The $P M$ strain of fixed rabies virus propagated in a stable line of neonatal hamster kidney fibroblasts $(B H K-21 \text {, clone } 13)^{2,3}$ was used for the experiments. Infectious tissue culture fluids were concentrated about twenty times by precipitation with zinc acetate ${ }^{1,4}$. Infectious virus was separated from "soluble" antigen(s) of rabies virus by high speed centrifugation $(4 \mathrm{~h}$ at 22,000 r.p.m., Spinco rotor $S W 25.1)^{1}$. $0.4 \mathrm{ml}$. of the supernatant fluid was layered over $4 \mathrm{ml}$. of a solution of eaesium chloride, adjusted by a phosphate buffer to $p \mathrm{H} 7 \cdot 0$, with a density of $1.22 \mathrm{~g} / \mathrm{cm}^{3}$ in a 'Lusteroid' tube for the Spinco $S W 39 L$ rotor. The mixture was centrifuged for $48 \mathrm{~h}$ at 34,000 r.p.m. Samples were collected after centrifugation by puncturing the bottom of the tube. The density of the samples was determined using a refractometer ${ }^{5}$, and the amount of antigen by a recently described fluorometric method ${ }^{6}$. The results in Fig. 1 show that the density of the "soluble" antigen(s) is about $1.26 \mathrm{~g} / \mathrm{cm}^{3}$, that is, it is higher than the density of infectious virus particles $\left(1 \cdot 20 \mathrm{~g} / \mathrm{cm}^{3}\right)^{1}$.

Rate zonal centrifugation was carried out in preformed sucrose gradients and the sedimentation coefficients were calculated essentially as described by Martin and Ames?. The sucrose solutions for preparing the gradient were buffered $(p \mathrm{H} 7.0)$ with phosphate buffer to a final concentration of 0.01 molar. $0.3 \mathrm{ml}$. of the suspension of "soluble" antigen(s) was layered on $4 \mathrm{ml}$. of a preformed sucrose gradient (10-20 per cent) in a tube for the Spinco $S W 39 L$ rotor. The mixture was centrifuged at 39,000 r.p.m. for $270 \mathrm{~min}$. The analysis of samples after centrifugation revealed two main peaks of antigen (Fig. 2), the position of which in the gradient would correspond to sedimentation coefficients of about 10 and $23 \mathrm{~S}$, respec-

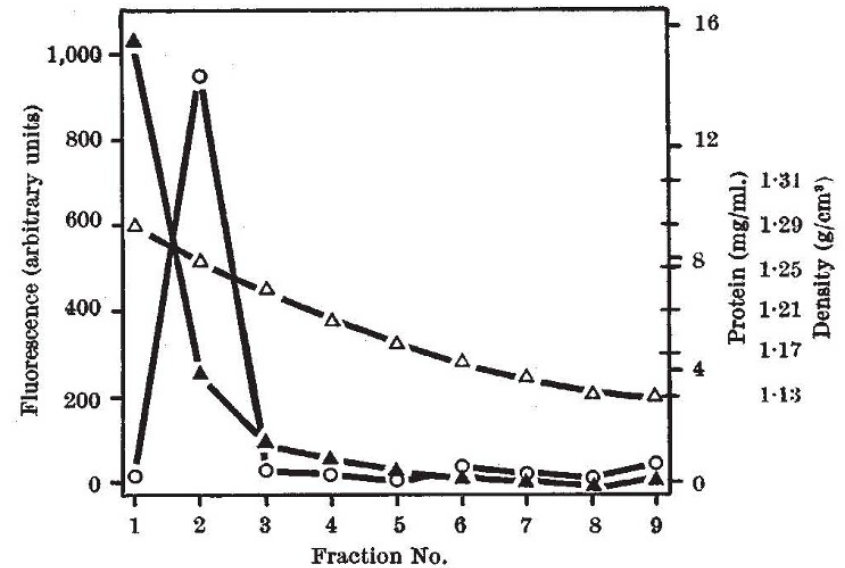

Fig. 1. Caesium chloride equilibrium density gradient centrifugation of rabies virus "soluble" antigens. Fraction 1, bottom: fraction 9, top. 0 , Concentration of antigen determined fluorometrically; $\mathbf{A}$, concentration of protein ${ }^{0} ; \Delta$, density.



Fig. 2. Rate zonal centrifugation of rabies virus "soluble" antigens in a preformed sucrose gradient. Fraction 1, bottom; fraction 14, top. tration of protein".

tively. This result is compatible with the demonstration of two precipitin lines by the Ouchterlony technique ${ }^{8}$.

It remains to be determined whether the "soluble" antigens have different or identical antigenic sites, whether and how they are related to the complete virion, and whether they are precursors, sub-units synthesized in excess or breakdown products of the virus. The elucidation of these problems is of considerable importance in view of the possibility of preparing an anti-rabies sub. unit vaccine.

I thank Dr. T. J. Wiktor of the Wistar Institute of Anatomy and Biology, Philadelphia, for supplying the infectious tissue culture fluids.

Research and Development Department,

\section{A. R. NFURAth}

Wyeth Laboratories, Inc.,

Radnor, Pennsylvania.

${ }^{1}$ Neurath, A. R., Wiktor, T. J., and Koprowski, H. (to be published).

2 Wiktor, T. J., Fernandes, M. V., and Koprowski, H., J. Immunol., 98, 353 (1965).

${ }^{3}$ Fernandes, M. V., Wiktor, T. J., and Koprowski, H., J. Exp. Med., 120. 1099 (1964).

- Sweet, B., and Spicer, D. (personal communication).

- Vinograd, J., and Hearst, J. E., in Progress in the Chemistry of Organic Natural Products (L. Zechmeister, ed.), 20, 372 (Springer, Vienna, 1962)

${ }^{6}$ Neurath, A. R., $Z$. Naturforsch., 20b, 974 (1965).

' Martin, R. G., and Ames, B. N., J. Biol. Chem., 236, 1372 (1961).

'Atanasiu, P., Lepine, P., and Purushotta, D., C.R. Acad. Sci., Paris, 256, 1415 (1963).

'Lowry, D. H., Rosebrough, N. J., Farr, A. L., and Randall, J., J. Biol. Chem., 198, 265 (1951). 